\title{
A Full-Size High-Temperature Superconducting Coil Employed in a Wind Turbine Generator Setup
}

Song, Xiaowei (Andy); Mijatovic, Nenad; Kellers, Jürgen; Bührer, Carsten; Rebsdorf, Anders V.; Hansen, Jesper; Christensen, Mogens; Krause, Jens; Wiezoreck, Jan; Pütz, Hendrik

Total number of authors:

11

Published in:

IEEE Transactions on Applied Superconductivity

Link to article, DOI:

10.1109/TASC.2017.2656627

Publication date:

2017

Document Version

Peer reviewed version

Link back to DTU Orbit

Citation (APA):

Song, X., Mijatovic, N., Kellers, J., Bührer, C., Rebsdorf, A. V., Hansen, J., Christensen, M., Krause, J.,

Wiezoreck, J., Pütz, H., \& Holbøll,, J. (2017). A Full-Size High-Temperature Superconducting Coil Employed in a Wind Turbine Generator Setup. IEEE Transactions on Applied Superconductivity, 27(4), [7828024].

https://doi.org/10.1109/TASC.2017.2656627

\section{General rights}

Copyright and moral rights for the publications made accessible in the public portal are retained by the authors and/or other copyright owners and it is a condition of accessing publications that users recognise and abide by the legal requirements associated with these rights.

- Users may download and print one copy of any publication from the public portal for the purpose of private study or research.

- You may not further distribute the material or use it for any profit-making activity or commercial gain

- You may freely distribute the URL identifying the publication in the public portal 


\title{
A Full-size High Temperature Superconducting Coil Employed in a Wind Turbine Generator Set-up
}

\author{
Xiaowei Song, Nenad Mijatovic, Member, IEEE, \\ Jürgen Kellers, Carsten Bührer, Anders V. Rebsdorf, Jesper Hansen, Mogens Christensen, \\ Jens Krause, Jan Wiezoreck, Hendrik Pütz, and Joachim Holbøll, Senior Member, IEEE
}

\begin{abstract}
A full-size stationary experimental set-up, which is a pole pair segment of a $2 \mathrm{MW}$ high temperature superconducting (HTS) wind turbine generator, has been built and tested under the HTS-GEN project in Denmark. The performance of the HTS coil is crucial to the set-up, and further to the development of the full generator. This paper deals with the HTS coil employed in the set-up. The coil utilizing YBCO tapes is double-layered with 152 turns per layer and is wound on a FeNi9 iron core. Several sensors are installed to monitor the operating status of the coil, e.g., temperature, field, voltage. The coil is tested in $\mathrm{LN}_{2}$ first, and then tested in the set-up so that the magnetic environment in a real generator is reflected. The experimental results are reported, followed by a finite element simulation and a discussion on the deviation of the results. The tested and estimated $I_{c}$ in $\mathbf{L N}_{2}$ are $148 \mathrm{~A}$ and $143 \mathrm{~A}$, respectively. When tested in the set-up, the maximum temperature of the coil is controlled at $77 \mathrm{~K}$ and $40 \mathrm{~K}$, and the $I-V$ curves under both conditions are presented. It is found that the lower half coil that is closer to the stator has a smaller $I_{c}$ due to a higher field level. The study is of significance to the development of HTS generators.
\end{abstract}

Index Terms - critical current, conduction-cooled, electromagnetic, full-size, high temperature superconducting generator, wind turbine.

\section{INTRODUCTION}

$\mathbf{H}$ IGH temperature superconducting (HTS) generators are expected to be a competitive drive train for large wind turbines [1]-[3]. Due to higher magnetic fields generated by HTS windings, HTS wind turbine generators possess higher torque densities than their conventional counterparts. Therefore, reduced volume and mass at the same power ratings could be achieved, and consequently, lower costs for transportation, installation, and foundation of large wind turbines are expected [4], [5]. Although study of HTS wind turbine generators has been of great interest and several designs have been proposed, the commercialization has not yet come. Demonstrations of key technologies associated with HTS wind turbine generators are needed to boost confidence and accelerate the commercialization.

HTS coils play a significant role in HTS generators. In partially superconducting generators, HTS coils serve as the field winding, and are always placed on the rotor [6]. The performance of the HTS coils has direct impact to the generator

X. Song, N. Mijatovic, and J. Holbøll are with the Center for Electric Power and Energy, Department of Electrical Engineering, Technical University of Denmark (DTU), 2800 Lyngby, Denmark (e-mail: song@elektro.dtu.dk).

J. Kellers, C. Bührer, J. Krause, J. Wiezoreck and H. Pütz are with ECO 5 GmbH, 53111 Bonn, Germany.

A. V. Rebsdorf, J. Hansen and M. Christensen are with Envision Energy Aps, 8600 Silkeborg, Denmark.

The work is supported by Innovation Fund Denmark (IFD) under the HTSGEN project. performance. Hence, in-depth investigation into HTS coils is essential to the development of HTS generators.

Study of a downscaled HTS coil is a good approach because it could offer an insight into design challenges and forecast potential risks at a low cost. J. Leclerc et al reported the testing of a sub-scale HTS coil for the application of wind turbine generators in [7]. The performance validation of such a coil could benefit the design and operation of real-scale HTS coils employed in generators. Nevertheless, several constraints exist in this approach. For example, in many cases, engineering challenges, e.g., the complexity of fabricating, assembling and operating a full-size HTS coil, could not be revealed factually by the downscaled approach.

Alternatively, the experience obtained from a full-size HTS coil, as well as its cryogenic system and protection system, could be directly implemented to a real HTS generator. G. Sarmiento et al dealt with the design and testing of a realscale $\mathrm{MgB}_{2}$ coil for the SUPRAPOWER $10 \mathrm{MW}$ wind turbine generator in [8]. Confirmed performance of the real-scale coil means that the coil design and manufacturing process are ready for industrial production. However, one downside in [8] is that the coil was not tested with the existence of iron poles and the stator. In other words, the magnetic environment of a real generator was not taken into consideration.

The HTS-GEN project, which was initiated in Denmark in 2013, aims at a full-size HTS generator set-up. The setup is based on a pole pair segment of a 2 MW HTS wind turbine generator. The investigation of the set-up could identify potential challenges and obtain practical knowledge before mass production of the full generator. This paper focuses on the full-size HTS coil employed in the set-up. The coil is tested in $\mathrm{LN}_{2}$ first, and then assembled into the set-up so that the coil is exposed to the magnetic environment of a real generator. Afterwards, a three-dimensional (3D) finite element (FE) simulation based on Ansoft is performed, and the deviation of the results between the test and the simulation is discussed.

\section{DESCRIPTION OF THE HTS COIL}

The cross section of the coil assembly is presented in Fig. 1. The coil utilizing YBCO tapes is double-layered with 152 turns per layer and is wound on a FeNi9 iron core. The iron core is integrated into the coil, so it is a so-called cold iron. The YBCO wires are insulated by wrapping $25 \mu \mathrm{m}$-thick Kapton tapes with $50 \%$ overlap. The two layers are further insulated by a $0.5 \mathrm{~mm}$-thick G10 spacer sheet in between. Two copper plates are placed at the top and bottom to enhance 
the thermal conduction property. Afterwards, two pressure plates are bolted to clamp the coil assembly with several side support elements. The pressure plates and side support elements are made of non-magnetic stainless steel. Throughout the manufacturing process, Apiezon type $\mathrm{N}$ cryogenic grease is used on solid interfaces to reduce contact thermal resistance. Fig. 2 is a picture of the finalized coil assembly. More details of the coil assembly are listed in Table I.

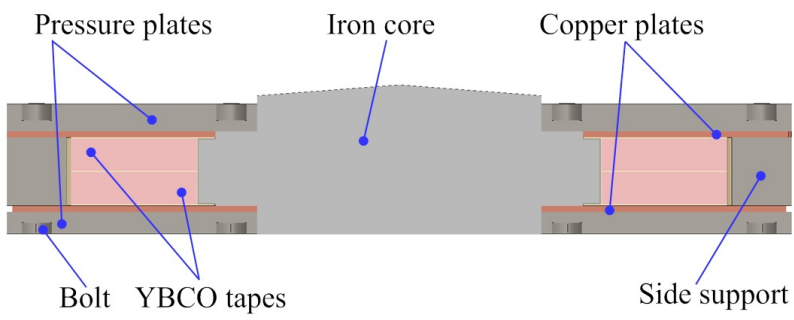

Fig. 1. Cross section of the coil assembly employed in a full-size HTS wind turbine generator set-up.

TABLE I

DETAILS OF THE COIL ASSEMBLY

\begin{tabular}{lc}
\hline \hline YBCO tape manufacturer & AMSC \\
Dimension of the YBCO tape $(\mathrm{mm} \times \mathrm{mm})$ & $12 \times 0.2$ \\
Stabilizer of the YBCO tape & Copper \\
Short sample $I_{c}(\mathrm{~A})$ & $350 @ 77 \mathrm{~K}$, self-field \\
Total amount of the tape $(\mathrm{m})$ & $\sim 650$ \\
Number of layers in the coil & 2 \\
Number of turns per layer & 152 \\
Width of the cold iron core $(\mathrm{mm})$ & 136 \\
Width of the coil (mm) & 46.5 \\
Height of the coil (mm) & 24.5 \\
Length of the coil straight part $(\mathrm{mm})$ & 698 \\
Inner radius of coil end part $(\mathrm{mm})$ & 75 \\
Outer radius of coil end part $(\mathrm{mm})$ & 121.5 \\
Thickness of the copper plates $(\mathrm{mm})$ & 2.3 \\
Thickness of the pressure plates $(\mathrm{mm})$ & 10 (upper) and 8 (lower) \\
Room temperature resistance $(\Omega)$ & 7.95 \\
Targeted operating temperature $(\mathrm{K})$ & $\sim 30$ \\
Targeted operating current $(\mathrm{A})$ & 480 \\
\hline \hline
\end{tabular}

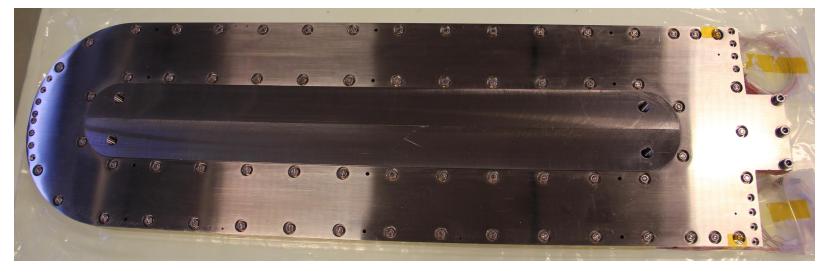

Fig. 2. Picture of the finalized coil assembly.

\section{EXPERIMENTS}

\section{A. Instrumentation}

Seven temperature sensors and three hall probes are built into the coil to monitor the temperature and the flux density. The positioning of these sensors are elaborated in Fig. 3.

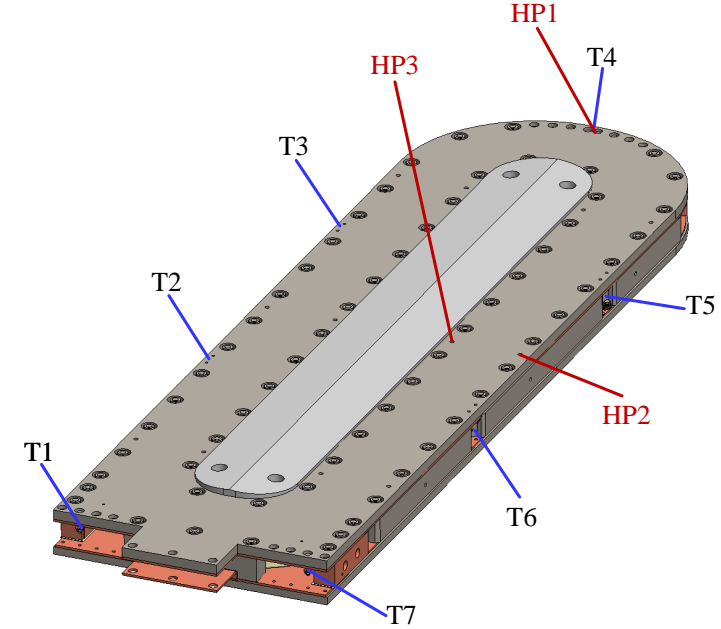

Fig. 3. The positioning of the built-in temperature sensors and hall probes.

The temperature sensors are LakeShore Cernox type CX1050 , and the calibration was performed before sensor installation. T1 and T7 monitor the temperature of the current terminals. T2, T3, T5, and T6 are evenly distributed along both sides of the coil straight part. T4 is placed at the far end of the coil, and it is supposed to give the highest reading because it has the longest thermal conduction path.

The Hall probes (Arepoc HHP-NP) are marked as HP1, HP2 and HP3 in Fig. 3. HP1 is horizontally positioned at the middle plane of the far end of the coil, and the local vertical field can be monitored. HP2 is horizontally placed at the outer side of the middle point along the coil straight part and gives the local vertical field measurement. HP3 is vertically installed at the inner side of the middle point along the coil straight part and measures the horizontal component of the local field.

The sketch of voltage tapes distribution is illustrated in Fig. 4. V1-V2 and V5-V6 are the voltages across the current terminals. Both V3 and V4 are soldered to the middle point of the whole coil. Therefore, V2-V3 and V4-V5 give the voltages of the upper half coil and the lower half coil, respectively. Note that the "lower" half coil here represents the upper layer shown in Fig. 1 since it will face the stator when assembled into the set-up later on.

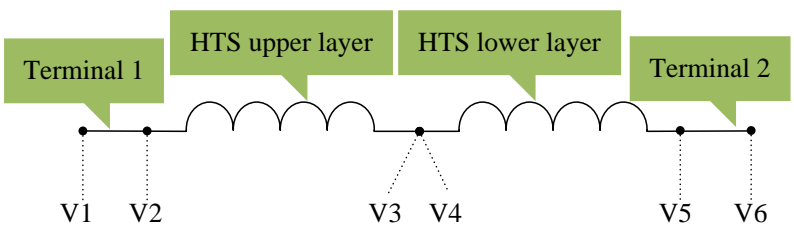

Fig. 4. Distribution of the voltage taps. V3 and V4 are soldered to the same point, i.e., the middle point of the whole coil. V2-V3 and V4-V5 give the voltages of the upper and lower half coils.

\section{B. Testing of the coil in $\mathrm{LN}_{2}$}

The coil was manufactured and assembled by HTS-110 in New Zealand, and then shipped to Denmark. Three tests in $\mathrm{LN}_{2}$ were carried out in total. The first two were performed by HTS-110 after finishing the coil assembling, and the third 
one was performed at DTU upon coil acceptance. The tested $I-V$ curves are shown in Fig. 5. Note that when tested in $\mathrm{LN}_{2}$, only the cold iron integrated into the coil is present.

As already illustrated in Fig. 4, V2-V5 gives the total voltage across the HTS coil. From Fig. 5, it is seen that the coil shows very little resistive voltage when the current is below $140 \mathrm{~A}$. The voltage then starts increasing steeply when the current is approaching to $146 \mathrm{~A}$ at which the coil voltage is $0.4 \mathrm{mV}$. The voltage finally goes to $1 \mathrm{mV}$ when the current is $150 \mathrm{~A}$. Although the voltage rise is not homogeneous along the HTS tape, using the criterion of $1 \mu \mathrm{V} / \mathrm{cm}, I_{c}$ is determined to be $148 \mathrm{~A}$. The voltage difference in Fig. 5, especially when the current is low, could be due to a system offset that partially comes from the residual inductive voltages, or from different accuracy levels of the testing equipment and noisy signals. In hindsight, longer settling time should have been given to excluded any inductive voltages. Shorter settling time is a compromise due to the time constraint of performing the test.

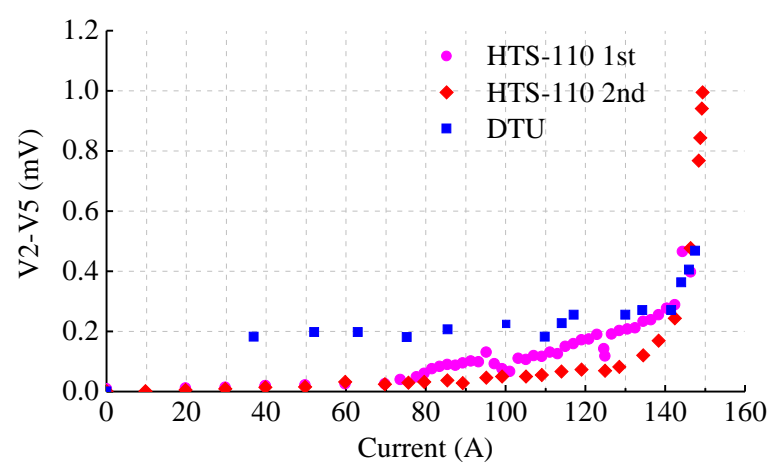

Fig. 5. Tested $I-V$ curves of the coil in $\mathrm{LN}_{2} . I_{c}$ is determined to be $148 \mathrm{~A}$.

\section{Testing of the coil in the Set-up}

After the tests in $\mathrm{LN}_{2}$, the coil was then assembled into the set-up, which is a pole pair segment of a 2 MW HTS wind turbine generator.

The coil and the integrated cold iron were wrapped with multi-layer insulation (MLI) to reduce radiative heat load. After that, the coil assembly was enclosed into the cryostat, together with the rotor back iron and the warm iron poles. Glass fiber reinforced plastic (GFRP) rods are utilized to support the coil. Fig. 6 shows the scene inside of the cryostat. Afterwards, a section of a conventional three-phase stator is placed below the cryostat, and an HTS generator set-up is then completed in the lab, as shown in Fig. 7.

The coil is conduction-cooled when tested in the set-up, and the targeted operating temperature is $30 \mathrm{~K}$. Two singlestage Gifford-McMahon (GM) cryocoolers CH-110 LT from Sumitomo are equipped. Before running at $30 \mathrm{~K}$, the coil was tested at $77 \mathrm{~K}$ and $40 \mathrm{~K}$ to assess the coil performance. The coil temperature is controlled by adjusting the dissipating power of the heaters installed on the cold heads. Since the coil is conduction-cooled, a temperature gradient exist in the coil. Therefore, T4, which has the highest temperature reading among all temperature sensors, is selected as the control object.

The tested $I-V$ curves when T4 is controlled at $77 \mathrm{~K}$ and $40 \mathrm{~K}$ are plotted in Fig. 8. The voltages of the half coils,

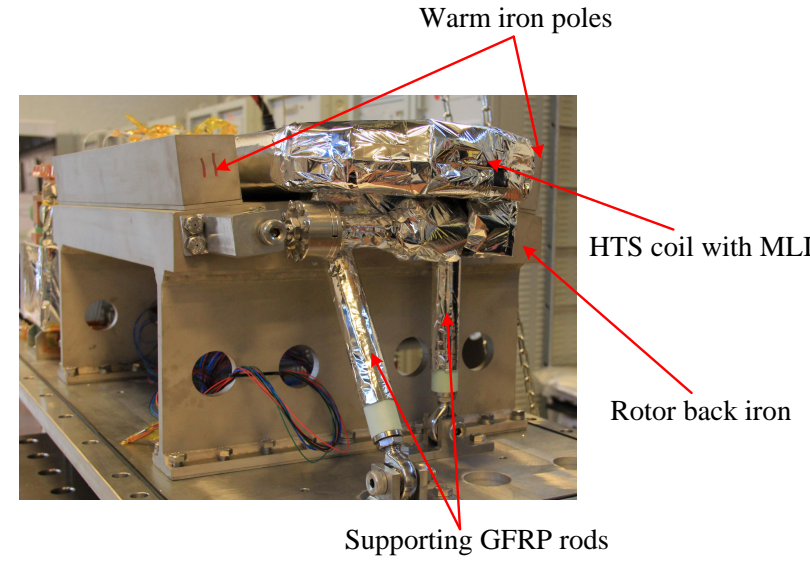

Fig. 6. Scene inside of the cryostat.

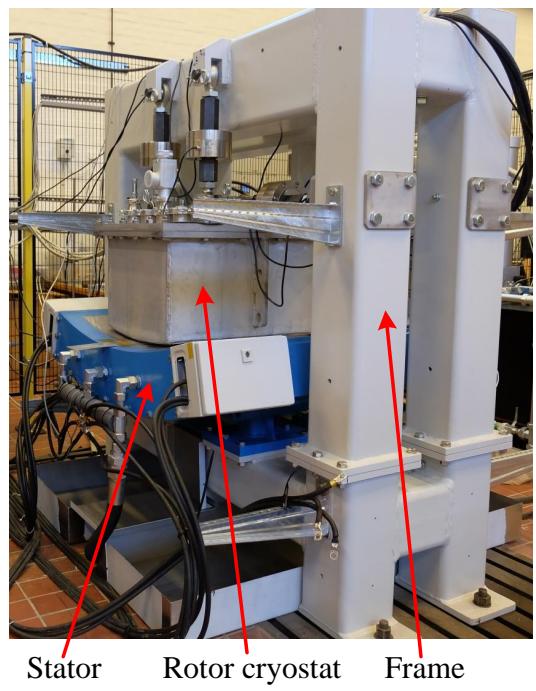

Fig. 7. The set-up completed in the lab. The HTS coil is enclosed in the cryostat.

i.e., V2-V3 and V4-V5, are measured. Note that when T4 is controlled at $40 \mathrm{~K}$, the current is plotted from $365 \mathrm{~A}$ since the measurements are merely noisy signals when the current is low. As indicated in Fig. 8, V4-V5 shows obvious voltage increase earlier than V2-V3 does, which means that the half coil facing the stator has a lower critical current. This can be further proved by the FE electromagnetic study in the following section. Because obvious voltage transitions already occurred, the currents were stopped at $133 \mathrm{~A}$ (when T4 is $77 \mathrm{~K}$ ) and $485 \mathrm{~A}$ (when T4 is $40 \mathrm{~K}$ ) to avoid risks of damaging the coil.

\section{SIMULATION AND DISCUSSION}

In this section, a 3D FE electromagnetic simulation based on Ansoft is reported, and the results are compared to the tested ones. The 3D FE electromagnetic model is presented in Fig. 9. Only a quarter of the real model is studied due to the symmetry.

If only the HTS coil and the cold iron core exist in the model, it corresponds to the situation that the coil is immersed in $\mathrm{LN}_{2}$, and the coil has a homogeneous temperature 


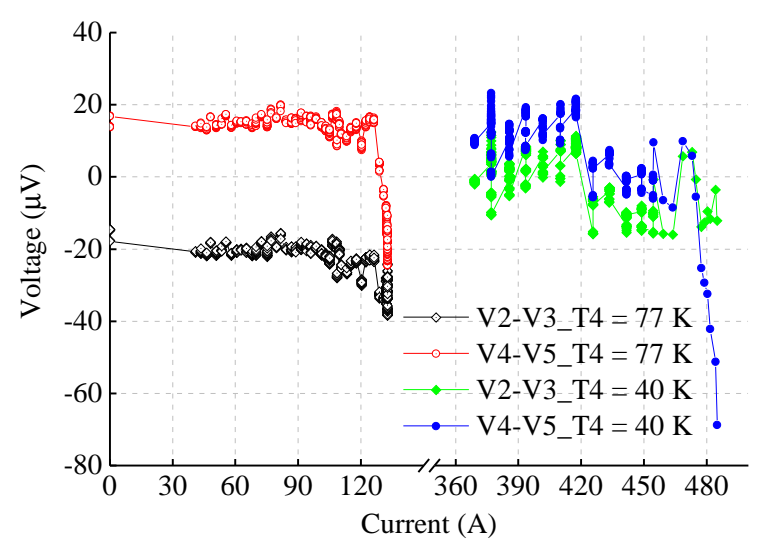

Fig. 8. Tested $I-V$ curve of the coil when $\mathrm{T} 4$ is controlled at $77 \mathrm{~K}$ and $40 \mathrm{~K}$. Obvious voltage transitions occur at $133 \mathrm{~A}$ (when T4 is $77 \mathrm{~K}$ ) and $485 \mathrm{~A}$ (when T4 is $40 \mathrm{~K}$ ).

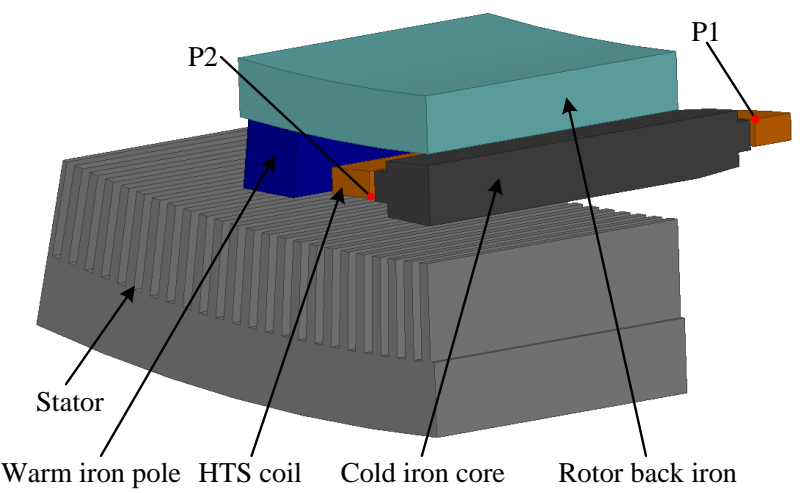

Fig. 9. 3D FE electromagnetic model in Ansoft. Only a quarter of the real model is studied due to the symmetry. P1 and P2 are respectively the locations where the highest perpendicular fields to the HTS tape occur when the coil is immersed in $\mathrm{LN}_{2}$ and when it is assembled into the set-up.

distribution. The FE simulation shows that in this case the highest perpendicular field to the HTS tape occurs at the top corner in the middle of the end turns, as marked with $\mathrm{P} 1$ in Fig. 9. Referring to the $I_{c}-B$ curves provided by AMSC, the critical current of the coil in $\mathrm{LN}_{2}$ is estimated to be $143 \mathrm{~A}$, as indicated by the crossing point between the $I_{c}$ line at $77 \mathrm{~K}$ and the load line of P1 in Fig. 10. Compared to the tested result presented in Fig. 5, the deviation is $3.4 \%$, which is at an acceptable level.

When the coil is assembled into the set-up, the field distribution changes due to the influence of the warm iron poles, the rotor back iron, and the stator. The FE simulation found that the lower half coil, which is closer to the stator, experiences a higher field level. Consequently, the lower half coil has a smaller critical current, which is consistent with the experimental findings in Fig. 8. The position that has the maximum perpendicular field to the HTS tape lies at the bottom corner in the middle plane of the coil straight part, as marked with P2 in Fig. 9. The critical lines at $77 \mathrm{~K}$ and $40 \mathrm{~K}$ cross the load line of P2 at $130 \mathrm{~A}$ and $500 \mathrm{~A}$, respectively.

Compared to the tested results, it is seen that the estimated critical currents at $77 \mathrm{~K}$ and $40 \mathrm{~K}$ from the $\mathrm{FE}$ simulation deviate from the experimental values by $2.3 \%$ and $3.1 \%$, respectively. The reason for the limited deviation is that the $I_{c}$ lines in Fig. 9 are based on short samples, and the criterion

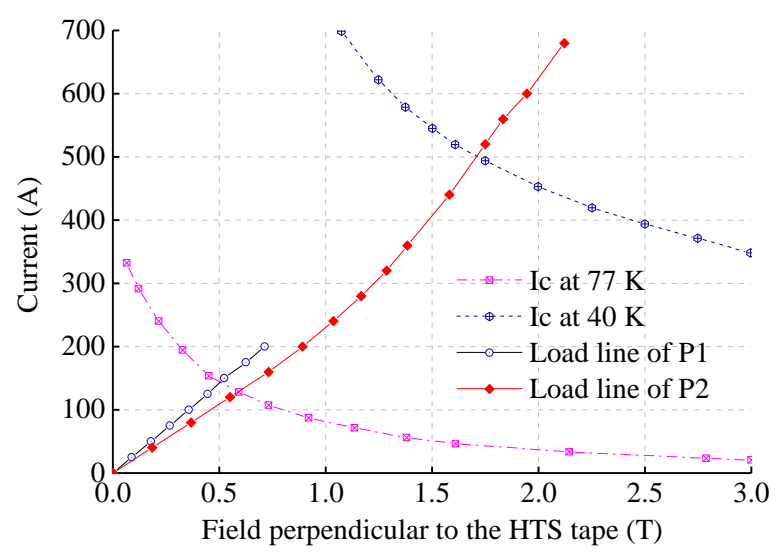

Fig. 10. Load lines from 3D FE simulation. P1 is the limiting point when the coil is immersed in $\mathrm{LN}_{2}$, while $\mathrm{P} 2$ is the limiting point when the coil is assembled into the set-up. The $I_{c}$ line at $77 \mathrm{~K}$ crosses the load line of P1 at $143 \mathrm{~A}$. The $\mathrm{I}_{\mathrm{c}}$ lines at $77 \mathrm{~K}$ and $40 \mathrm{~K}$ cross the load line of $\mathrm{P} 2$ at $130 \mathrm{~A}$ and 500 A, respectively.

of $1 \mu \mathrm{V} / \mathrm{cm}$ is used. However, during the experiments, the currents were stopped quite early for the safety reason, and the criterion of judging the critical current has changed.

It is necessary to point out that the temperature of $\mathrm{P} 2$, noted as $\mathrm{T}_{\mathrm{P} 2}$, is lower than $\mathrm{T} 4$ due to the temperature gradient in the coil. Recalling the positioning of the temperature sensors elaborated in Fig. 3, it is reasonable to assume $\mathrm{T}_{\mathrm{P} 2}=(\mathrm{T} 2+$ $\mathrm{T} 3+\mathrm{T} 5+\mathrm{T} 6) / 4$. In consequence, $\mathrm{T}_{\mathrm{P} 2}$ is $75 \mathrm{~K}$ when $\mathrm{T} 4$ is $77 \mathrm{~K}$, and $\mathrm{T}_{\mathrm{P} 2}$ is $39 \mathrm{~K}$ when $\mathrm{T} 4$ is $40 \mathrm{~K}$. Unfortunately, the critical lines at $75 \mathrm{~K}$ and $39 \mathrm{~K}$ are not available, which makes it difficult to further correct the estimated critical currents. Some other factors, e.g., angular dependency of $I_{c}$, also contribute to the deviation [9], [10]. Since such study would exceed the volume of this paper, it will be addressed in our further work.

\section{CONClusion}

A full-size HTS coil employed in an HTS wind turbine generator set-up is reported. The specifications of the coil are presented, followed by the testing of the coil. The coil was first tested in $\mathrm{LN}_{2}$, and then tested in the set-up with the existence of the magnetic environment in a real generator. Afterwards, a 3D FE simulation based on Ansoft is performed to assess the critical currents of the coil.

The tested and estimated $I_{c}$ in $\mathrm{LN}_{2}$ are $148 \mathrm{~A}$ and $143 \mathrm{~A}$, respectively. When tested in the set-up, the maximum temperature of the coil is controlled at $77 \mathrm{~K}$ and $40 \mathrm{~K}$. Obvious resistive voltages occur at $133 \mathrm{~A}$ under $77 \mathrm{~K}$, and $485 \mathrm{~A}$ under $40 \mathrm{~K}$. The lower half coil that is facing the stator is found to have a smaller $I_{c}$ due to a higher field level. The FE simulation gives $I_{c}$ of $130 \mathrm{~A}$ at $77 \mathrm{~K}$, and $500 \mathrm{~A}$ at $40 \mathrm{~K}$. The deviation between the simulation and the measurements could be resulted from the changed criterion of judging the critical current. The inevitable temperature gradient in the conduction-cooled coil and the unavailable $I_{c}$ values at $75 \mathrm{~K}$ and $39 \mathrm{~K}$ make it difficult to further correct the estimated critical currents. Considering the angular dependency could also give a more accurate estimation of the $I_{c}$ of the coil, and it will be addressed in future work.

The testing results when the stator is loaded will be reported later on. 


\section{ACKNOWLEDGEMENT}

The authors would like to acknowledge the financial support from Innovation Fund Denmark (IFD).

\section{REFERENCES}

[1] B. B. Jensen, N. Mijatovic, and A. B. Abrahamsen, "Development of superconducting wind turbine generators," J. Renew. Sustain. Energy, vol. 5, no. 2, Mar. 2013, Art. No. 023137.

[2] A. B. Abrahamsen, N. Mijatovic, E. Seiler, T. Zirngibl, C. Træholt, P. B. Nørgård, N. F. Pedersen, N. H. Andersen, and J. Østergaard, "Superconducting wind turbine generators," Supercond. Sci. Technol., vol. 23, no. 3, 2010, Art. No. 034019.

[3] R. Qu, Y. Liu, and J. Wang, "Review of superconducting generator topologies for direct-drive wind turbines," IEEE Trans. Appl. Supercond., vol. 23, no. 3, pp. $5201108-5201$ 108, Jun. 2013.

[4] G. Snitchler, B. Gamble, C. King, and P. Winn, "10 MW class superconductor wind turbine generators," IEEE Trans. Appl. Supercond., vol. 21, no. 3, pp. 1089-1092, Jun. 2011.

[5] S. S. Kalsi, "Superconducting wind turbine generator employing $\mathrm{MgB}_{2}$ windings both on rotor and stator," IEEE Trans. Appl. Supercond., vol. 24, no. 1, Feb. 2014, Art. No. 5201907.

[6] H. Karmaker, M. Ho, and D. Kulkarni, "Comparison between different design topologies for multi-megawatt direct drive wind generators using improved second generation high temperature superconductors," IEEE Trans. Appl. Supercond., vol. 25, no. 3, Jun. 2015, Art. No. 5201605.

[7] J. Leclerc and P. J. Masson, "Testing of a subscale HTS coil for wind turbine generator," IEEE Trans. Appl. Supercond., vol. 26, no. 3, Apr. 2016, Art. No. 5206304.

[8] G. Sarmiento, S. Sanz, A. Pujana, J. M. Merino, I. Marino, M. Tropeano, D. Nardelli, and G. Grasso, "Design and testing of real-scale $\mathrm{MgB}_{2}$ coils for SUPRAPOWER 10-MW wind generators," IEEE Trans. Appl. Supercond., vol. 26, no. 3, Apr. 2016, Art. No. 5203006.

[9] D. Turrioni, E. Barzi, V. Lombardo, C. Thieme, M. Lamm, and A. Zlobin, "Angular measurements of HTS critical current for high field solenoids," in AIP Conf. Proc., vol. 986, 2007, pp. 451-458.

[10] A. Xu, J. Jaroszynski, F. Kametani, Z. Chen, D. Larbalestier, Y. Viouchkov, Y. Chen, Y. Xie, and V. Selvamanickam, "Angular dependence of $\mathrm{J}_{\mathrm{c}}$ for $\mathrm{YBCO}$ coated conductors at low temperature and very high magnetic fields," Supercond. Sci. Technol., vol. 23, no. 1, p. 014003 , 2009. 